\title{
Cellular automata and consumer behaviour
}

\author{
JEAN-FrançoIs ROUHAUd ${ }^{1}$
}

\begin{abstract}
The concept of cellular automata originates in research by J. Von Neumann about forty years ago. Nevertheless, marketing applications remain scarce. That's why this paper analyses, with the help of a simulation model, how the use of cellular automata can visualize interactions between consumers and forecast the evolution of markets. The CAMAC model is characterized by an economic space as a bidimensional torus and consumers as multi-state probabilistic cellular automata able to go through as many different states as there are different competing products on the market. Various consumer behaviours are studied: nonconformism, following opinion leaders, sensitiveness to other individuals, brand loyalty, variety search, individual geographic and relational mobility, family size and internal purchase decision processes. Other socio-economic parameters such as the market size, the inter-individual distance, the number of competing products or the kind of goods are introduced. This model is tested and at last its limitations and its interest are pondered.
\end{abstract}

\section{Introduction}

The concept of cellular automata originates in research by Von Neumann and Ulam about forty years ago. But actual applications became visible only in the early 80's in a variety of areas: biology, chemistry, physics, ecology, urban dynamics, etc. The behavioural complexity stemming from the application of a few simple rules make this approach very attractive for many researchers.

A number of economic applications have been documented, especially related to explaining stock market behaviour and spreading innovation (Bhargava et al., 1993; Fuks and Boccara, 1995 and 1996 for studies in a unidimensional space), but they remain scarce. However, it appears that the possibility of representing individual behaviours by means of an automata network that takes interactions into account opens new avenues both for economic theory and marketing. For traditional micro-economic approaches take individuals as purely rational entities who make decisions irrespective of what their neighbours do, while marketing approaches, necessarily more action-oriented, do integrate interdependencies : such notions as 'family', 'opinion leader', 'reference group',

\footnotetext{
${ }^{1}$ I.U.T. Département G.E.A., University of Poitiers, 8, rue des Carmes, 86012 Poitiers Cedex, France. E-mail: jfr@ ricky.univ-poitiers.fr Keywords: Cellular automata, consumer behaviour, marketing, modeling, simulation.
} 
'vicarious learning' are indeed analysed and integrated into some consumer behaviour models (Dubois, 1995; Engel et al., 1993; Solomon, 1995). Bass's mixed influence model (1969) and its sequels ( $c f$. for a review El Ouardighi and Tapiero, 1997) incorporate various numbers of those ingredients. But cellular automata can help represent visually and accurately phenomena involving a number of interdependent units everywhere where the notion of distance (whether in be spatial or relational) is relevant and time treated as discrete. Within that view, resorting to automata networks seems to provide us with a consistent framework for the study of consumer interactions on a market. On the basis of a few elementary rules, the evolution of a market can thus be simulated, its path calculated and its final state defined.

Researchers have devised models that provided for that end. Deissenberg (1996) has proposed a network of consumer-cellular automata incorporating proximate relations in a hexagonal space. Similarly, market time path study allow Robert-Demontrond and Thiel (1996) to forecast a market's dynamic properties through automata network simulation.

The main purpose of this paper is to analyse how the use of cellular automata can help modelizing interactions between consumers involving more complex economic or psychological behaviours. Its secondary aim is the study of specific market trends for each kind of rule, and conclusions about the future of such markets. The CAMAC (Cellular Automata Model Applied to Consumption) model has been devised to this exploratory end. A standard version of the model is first presented, then a number of rules of behaviours and environment are proposed and tested. Finally, suggestions for application to more complex universes will be made.

\section{How cellular automata work}

The general principle involved is a simple one. Consumers are represented by probabilistic cellular automata, moving inside a codified space-time continuum (a bidimensional torus), and depending on various behavioural rules. They may go through several states, each state representing the purchase or use of a specific product at a moment $t$.

\subsection{Space-time characteristics}

The relevant space is a bidimensional torus. Indeed, taking two dimensions into account contributes to enhanced realism and more diversified situations than a one-dimension framework such as some researchers use. Moreover, a torus will make irrelevant the problems linked to edges.

The space itself is orthogonal. Each cell in it is surrounded by 8 neighbouring cells that rule its behaviour (the so-called Moore neighbourhood). This very classical representation allows for multiple influences. Other solutions might be implemented, such as a hexagonal space (6 neighbouring cells), Von Neumann's neighbourhood (4 neighbouring cells), other neighbourhoods based on a higher than 1 radius (hence involving an even higher number of neighbouring cells), or even spaces with more than 2 dimensions, generating a hypertorus. 
Time, like space, is discrete in nature. The state of a given cell at $t$ (whether it be instant or period) depends on its neighbouring cells' states at $t-1$, and possibly, according to the applied transition rule, to the state of the cell itself at $t-1$, which will induce a memorisation phenomenon.

That space is the locus of inter-individual distances. Those are not necessarily geographical, but may be social or relational. In that sense, the automaton network can be compared to a sociogram.

\subsection{Consumers as multi-state probabilistic cellular automata}

Each consumer is represented by one cell in the torus. The value taken by the cell at $t$ is an indicator of the action (e.g. product purchase).

The behaviour of a probabilistic automaton is predicted by a probability law. Each individual, for each $t$, will make a choice among a range of products according to the choices made by its neighbours during $t-1$.

The likelihood of product $j$ being chosen by individual $i$ for $t$, i.e. the likelihood for cell $i$ to be in state $j$ at $t$ is written:

$$
p_{j, i, t}=V_{j, t-1} / V_{i}
$$

where $V_{j, t-1}$ is the number of $i$ 's neighbours who choose product $j$ at $t-1$ and $V_{i}$ is the number of $i$ 's neighbours.

The resulting behaviour is one of imitation of neighbours, a standard case in reference and vicarious learning groups ( $c f$. for a marketing study of such situations Nord and Peter, 1980).

The deterministic choice hypothesis was discarded, as it postulates the consumer's perfect rationality and consistency of behaviour, which sounds quite unrealistic.

The cellular automata can go through as many different states as there are different competing products on the market.

The consumer purchases a product which is renewed for each $t$. That hypothesis is a cornerstone of the standard model, and will be dispensed with later.

\subsection{The initial configuration}

The initial state of each cell $(t=0)$ can be randomly determined, according to a given probability distribution or a predetermined framework stemming from a particular hypothesis.

\subsection{Market time path}

As operations are repeated, the state of the cells evolves, patterns may emerge and choice frequency change. Automata network dynamics will normally lead to a final configuration matching one of the 4 categories defined by Wolfram (1986): fixed and homogeneous states, simple periodic structures, chaotic and aperiodic structures, complex structures. Conclusions about long-term trends in some markets may then be drawn. 


\subsection{General structure of algorithm}

The algorithm used in the CAMAC model may be described as follows:

\section{Phase 1: Initialisation}

nt: number of periods in the simulation

$t=0$

Parameter values (space type, number of cells)

Initial state of cells (random or deterministic)

Cell initial state display

Phase 2: $t=t+1$

Phase 3: Transition rule

For each cell

Observation of neighbouring cells' states at $t-1$

Application of chosen transition rule

New state of cell

Cell new state display

Phase 4: If $t<$ nt then go back to phase 2

Phase 5: End

Result display

The transition rule, in the standard version of the model, reflects the neighbour imitation behaviour, and is written:

$$
e_{i, t}=f\left(p\left(e_{v, t-1}\right)\right)
$$

where $e_{i, t}$ is the state of the cell at $t ; v, i$ 's neighbourhood; $e_{v, t-1}$, the vector of cell states of $v$ at $t-1 ; p$, the vector of probabilities pertaining to $v$ 's cell states; and $f$, the function giving $e_{i, t}$, s value according to $p$.

Other more complex transition rules will be proposed further on, which will help modelise various situations.

\subsection{Testing the standard algorithm}

\section{Testing conditions}

The standard algorithm and its variants was tested in series of 30 simulations involving a given parameter group.

The number of simulated individuals is 576 , spread over a torus whose flat equivalent would be a 24-cell side square.

Moore's neighbourhood prevails. 
The number of states np (products between which consumers may choose) is 3 , which was deemed preferable to 2 as it licenses the testing of more complex market situations. Maximum duration for simulations is 9,999 periods.

Initial configuration setting is done randomly as each individual is given a choice of products with a probability of $1 / \mathrm{np}$, i.e. $1 / 3$.

\section{Test results}

All simulations show the same characteristic evolution in 3 unequal phases.

The first phase is short (about 20 periods): cells display quasi-random values.

The second phase's length is variable (about 20 to 200 periods). During that phase, fuzzy fluctuating structures appear, reflecting the 'neighbourhood coherence' principle proposed by Phipps (Phipps, 1989; Langlois and Phipps, 1997), which states that 'in a system of interactive cells, the state achieved in one cell tends to take over the neighbouring cells'. That phase ends with the elimination of one product.

The third phase, which is at least as long as the combined first two, reflects a monopoly situation. For a significantly long time, the influence struggle between the 2 remaining products is indecisive, but invariably ends with the elimination of one.

The final configuration thus matches Wolfram's class 1 attractors. On average, it is achieved after 441 repetitions, with a standard deviation of 332.

An economic interpretation, which however shouldn't be over-generalised, thus shows an inescapable trend towards concentration in a competition situation, as soon as the assumed imitation behaviour is an individual feature.

\section{Market segmentation}

Random initialisation of a set of consumers implies those being homogeneously spread in the space of socio-economic relations. The reality is, of course, far less clear-cut. Geographic isolates, the existence of a culture- or income-based spatial or relational segregation, social or economic preferences all contribute to making the hypothesis of a random spread of individuals a highly unrealistic one.

In terms of a cellular automata network, initial market segmentation on geographic or socio-economic criteria can be obtained by allocating each product's consumption to a specific area in the torus.

\section{Adopted rule}

$e_{i, 0}=e_{p, 0}$ where $p, 0$ is an area where only product $p$ is consumed at instant 0 .

Variants of such a rule might be used to account for specific situations:

- areas where it is mostly though not exclusively product $p$ that is initially consumed,

- areas separated by obstacles with parametrable manageability. 
Test

Initial market segmentation between 3 products consumed by 3 distinct areas show an evolution that is quite similar to the initial model's, albeit with slower convergence. Even so, the difference between observed averages is not significant.

\section{Alternative relational behaviours}

Other behaviours than the mere imitation of neighbours can be assumed: nonconformism, the following of opinion leaders, and sensitiveness to other individuals.

\subsection{Nonconformism}

It is defined as the reverse of imitation behaviour. Nonconformist individuals will regularly choose the minority consumption mode in his neighbourhood.

\section{Adopted rule}

Let $e_{i, t}=f\left(1-p\left(e_{v, t-1}\right)\right)$

\section{Test (cf. Appendix 1)}

If the nonconformist behaviour is extended to all consumers (which may sound paradoxical), then market evolution becomes dependent on a global change of state for all cells and each period. A more or less regular alternation is observed as no product becomes dominant ( $c f$. Wolfram's class 2).

If the nonconformist behaviour is limited to a minority of consumers (1/24), market evolution becomes chaotic as no product becomes dominant ( $c f$. Wolfram's class 3 ).

Nonconformists thus appear as likely to block the market convergence process. A minority of them is enough to maintain a situation of unstructured competition.

\subsection{Following opinion leaders}

The following of neighbouring opinion leaders should logically entail the sales expansion of products consumed or prescribed by the leader.

\section{Adopted rule}

If there is an opinion leader in a consumer's neighbourhood, then the consumer will buy the product consumed by the leader.

Let $e_{i, t}=e_{o, t}$ where $\mathrm{o} \in v$ and $e_{o, t}$ is the state of the opinion leader at $t$. 
Other rules might be posited, notably:

- the existence of an opinion leader whose neighbourhood would only react through a rise in the likelihood of choice of the product consumed by the leader;

- the influence of an opinion leader reaching beyond the consumer's neighbourhood radius (e.g. some stars' media power).

\section{Test}

The existence of specific opinion leaders for any one product will inevitably result in the domination of that product ( $c f$. Appendix 1). This result is, of course, a function of the rule giving the dependency relation to the leader.

\subsection{Sensitiveness to other individuals}

Sensitiveness to other individuals entails an increase in the psychological importance given to neighbourhood actions. That behaviour increases the number of connections linking sensitive individuals to other individuals.

In terms of cellular automata, that phenomenon can be represented by an alteration in the rules defining neighbourhood and the spatial density of individuals.

\subsubsection{Altering neighbourhood rules}

Von Neumann's neighbourhood, which is limited to the 4 orthogonally adjacent cells, reduces connectivity by $50 \%$ compared to Moore's neighbourhood.

Moreover, it has an increasing effect on inter-cell distances.

Indeed, with Von Neumann's neighbourhood, the distance between individuals $A$ and $B$ is a rectilinear distance written:

where $X_{a b}=\left|X_{a}-X_{b}\right|$ and $Y_{a b}=\left|Y_{a}-Y_{b}\right|$.

$$
d(A, B)=X_{a b}+Y_{a b}
$$

With Moore's neighbourhood, the $A-B$ distance becomes:

$$
d(A, B)=\sup \left(X_{a b}, Y_{a b}\right)
$$

Hence, the distance between $A$ and $B$ when located on a portion of a torus like:

\section{$\mathrm{O}$ B O O O \\ $\mathrm{OOOOAO}$}

is written $d(A, B)=3+1=4$, with Von Neumann's neighbourhood, and $d(A, B)=$ $\sup (3,1)=3$ with Moore's neighbourhood.

That phenomenon can slow down a potential convergence of the network.

Other types of neighbourhood, random and/or taking various shapes, might also be applied ( $c f$. Margolus and Toffoli, 1987).

The increase in the neighbourhood radius $R$ is yet another type of neighbourhood alteration.

The initial model is based on $R=1$.

With Moore's neighbourhood, the number of neighbours is $(2 R+1)^{2}-1$, i.e. 24 neighbours for $R=2$ and 48 for $R=3$. In order to take account of the variable intensity of 
inter-individual relations, the influence of such neighbours might be weighted according to $1 / D^{2}$ where $D$ is the consumer-neighbour distance.

\subsubsection{Density decrease of individuals on torus}

A decrease in the number of individuals on an unchanged torus will decrease average connectivity to the same extent. If individuals are spread randomly, the number of connections per individual may vary enormously (e.g. from 0 to 8 with Moore's neighbourhood).

\subsubsection{Test}

The decrease in average connectivity involved by Von Neumann's neighbourhood entails market instability (elimination of one of the 3 products, then an oscillating checkerboard pattern with full alternation of states in all cells) in $33 \%$ of simulations. In the other cases, total domination of one product is observed after a longer period of time than with Moore's neighbourhood.

With Moore's neighbourhood, a 50\% density decrease will generally result in a 'freeze' of important areas in the torus and a domination of one of the products, though not an absolute domination in $80 \%$ of simulations.

\section{Non-relational behaviours having direct impact on product choice}

Two types of contradictory behaviours will be discussed: brand loyalty and the search for alternatives.

\subsection{Brand loyalty}

Brand loyalty has long been a staple ingredient in the practice of marketing specialists. It features the idea of an individual memory.

\section{Adopted rule}

The likelihood of a choice made by the individual $i$ at $t$ being identical to that made at $t-1$ is $p(w<\varphi)$, with $w$ a random variable according to a probability law $p$ constant between 0 and 1 , and $\varphi$ a product loyalty index such as $0<\varphi<1$.

Let $e_{i, t}=f\left(\varphi e_{i, t-1}+(1-\varphi) p\left(e_{v, t}\right)\right)$

Numerous variants can be imagined, notably:

- a specific loyalty index for each individual (as opposed to a global one);

- a same choice by $i$ renewed for a number a periods, with a change occurring only after long and variable periods of time; 
- a same choice renewed by $i$ except when a cognitive dissonance phenomenon occurs that will lead $i$ to change its purchasing habits.

Test

The tests made for $\varphi=0.9$ show a slowdown of the evolution towards the domination of one product. However, such domination is generally ineluctable.

\subsection{Variety search}

That behaviour has been the subject of numerous studies ( $c f$. Ter Haserborg and Massen, 1998 , for a recent synthesis). Contrary to the previous behaviour, the search for alternatives implies purchases that are, when possible, not identically renewed, or diversified purchases to answer the heterogeneous needs of a family.

\section{Adopted rule}

Each individual will seek to consume a different product from the previous period's and will imitate his neighbourhood if no such product is available.

Let $e_{i, t}=f\left(e_{i, t-1}, p\left(e_{v, t-1}\right)\right)$ with, if possible, $e_{i, t}<>e_{i, t-1}$

Some alternative rules might be posited:

- an alternative search behaviour applied as a function of a probability law;

- an alternative search behaviour applied without any reference to neighbourhood (that hypothesis, if generalised, would destroy the main originality of cellular automata, individuals' interactivity);

- a multi-period alternative search behaviour based on the type of products consumed during $p$ previous periods.

\section{Test}

Generalising such behaviour to all individuals will generate chaotic structures.

If such behaviour only pertains to a minority of individuals, the elimination of one of the 3 products will occur rather quickly. Henceforward, it's a chaotic fluctuation pattern that will characterise market time path.

\section{Non-relational behaviours having indirect impact on product choice}

Those can take various shapes: lifestyle, family life cycle, personality, beliefs and attitudes, etc.

Three factors were built into the CAMAC model: individual mobility, family size, and internal decision processes within the family. 


\subsection{Individual mobility}

That mobility can be geographic and/or relational and socio-economic. In terms of cellular automata, it is represented by relevant individuals moving throughout the torus, hence an alteration of their neighbourhood.

\section{Adopted rule}

Each period $t$, a random set of $m$ individuals $i$ is made to move. Those exchange coordinates, thus making the moving distance variable and random.

Let $X_{i, t}<>X_{i, t-1}$ and/or $Y_{i, t}=\left\langle>Y_{i, t-1}\right.$

where $X_{i, t}$ and $Y_{i, t}$ are individual $i$ 's coordinates on the torus.

The main alternative rules applicable would be:

- limiting moving distance to one cell a period;

- the randomhood of the number $m$ of mobile individuals.

\section{Test (cf. Appendix 2)}

Generalised mobility being quite unrealistic, a test was made with a mere $1 / 12$ of the population considered as mobile. No alteration in the initial attractor was observed, but a slowdown in convergence appears. Thus, increased individual mobility would curb product elimination processes.

\subsection{Family size and internal purchase decision processes}

Family size and the decision making process are linked as regards their impact on product purchase. For a determined number of consumers, the average size of families may not have any influence on purchased goods volume, but the internal decision process may affect choices. In this respect, a society where everyday purchases are made by the mother alone will most probably result in very different choices from those in a society where, average family size being constant, choices are individually made by each member of the family.

\section{Adopted rule}

Family size is represented by the clustering of a number of cells whose evolution is dependent on rules reflecting purchase decision processes. For instance, a 4-cell square can simulate the average nuclear family, a 9-cell square a traditional patriarchal family.

The internal purchase decision process can be an autocratic one (the 'breadwinner' will decide on his own by observing his neighbourhood's behaviour), a centralised democratic one (product choice is made on an internal family vote), or a decentralised democratic one (each family member deciding on his own without consulting other members).

The main alternative rules applicable are: geographically or socially mobile families; variable size and behaviour families; more complex purchasing decisions. 


\section{Test (cf. Appendix 2)}

The tests conducted show a clear-cut relation between family size and the speed at which products are eliminated from the market. A society made of small families would undergo a slower rate of industrial and commercial concentration.

It also emerges that a decentralised democratic family decision mode is a slowdown factor in the convergence towards a stable state.

\section{Other socio-economic parameters}

Four more parameters were studied: market size, inter-individual distances, the number of competing products and the existence of durable goods.

\subsection{Market size}

Market size will a priori exert considerable influence not only on purchase volume, but also on purchase variety. A large market can then be expected to allow a lot more brands to survive than a smaller market.

Tests conducted ( $c f$. Appendix 3) confirm that intuition and show the slower convergence observed on large markets.

\subsection{Inter-individual distance}

Increased spatial or socio-economic distances look likely to encourage the maintaining of specific consumption modes within certain groups.

The test conducted ( $c f$. Appendix 3 ) consisted in comparing the standard market (a $24 \times 24$ torus where maximum inter-individual distance is, using Moore's neighbourhood, $d \max =\sup (\mathrm{nx} / 2, \mathrm{ny} / 2)$ with $\mathrm{nx}$ and ny $=24$, i.e. $d \max =12)$ and a more scattered market (an $8 \times 72$ cell torus where maximum distance becomes 36 ). That test corroborates the hypothesis.

\subsection{Number of competing products}

Market time paths observed in the standard model go through different product elimination phases.

The positive relationship between the number of products initially present on the market and the number of repetitions needed to achieve a stable final state is confirmed by testing ( $c f$. the comparison of 2, 3, 4 product variants in Appendix 3).

\subsection{Durable goods}

A durable good, by definition, is only renewed after lengthy periods of time. Therefore, the evolution of the system that describes the market should be slowed down. 
The test consisted in assuming the renewing of products every 10 periods. Each consumer was randomly initialised, i.e. repurchase individual dates are not simultaneous.

Tests conducted ( $c f$. Appendix 3) significantly confirm that a durable goods market will show slower convergence.

\section{Mixed simulation models}

The various factors just examined may be combined to modelise a much less theoretical market. For instance, two variants including 4 products and purchases made each period have been tested: a 'traditional society' variant and a 'transitional modern society' one.

\section{Hypothesis}

Traditional society: 576 individuals in 64 autocratic 9-member families, segmented initial distribution, high brand loyalty $(\varphi=0.9)$, no variety search, Von Neumann's neighbourhood, no individual mobility.

Transitional modern society: 576 individuals in 144 autocratic, 4-member families, random initial distribution, zero brand loyalty $(\varphi=0)$, variety search $(1 / 24$ of population), Moore's neighbourhood, individual mobility.

\section{Results}

Traditional society: a very slow convergence towards a stable state can be observed, characterised by a long duopoly involving a leader and a challenger, with the latter eventually disappearing after an average 5,226 periods (standard deviation: 1,777 ).

Modern society: a generally quick disappearance of 2 in 4 products is observed, together with the institution of a chaotic pattern of comparative balance between the 2 remaining products for more than 2,000 periods, which highlights, among other things, the homeostatic properties of variety search, as well as the role of individual mobility. The elimination of the third product occurs after 2,636 periods on average (standard deviation: 1,606$)$.

\section{Prospects and conclusion}

The CAMAC model is but a metaphor of consumer goods markets. Its limitations are obvious: the postulate of neighbourhood interactions characterising cellular automata, the mechanist and static nature of individual behaviours, the mode of representation of time, and, broadly speaking, the long-standing philosophical enigma of the correspondence between the mathematical version of a given problem and the real world, discussed by Casti (1991) among others. Moreover, it only points out long-term trends. It is an exploratory model yet to be experimentally validated.

For all those caveats, the interest of using cellular automata networks is quite clear. On the basis of the individual imitation behaviour postulate, the model contributes to the 
experimental deduction of economic relations such as market convergence towards a monopoly situation and their potential instability.

This kind of model, offering an array of tools, can be easily supplemented to account for a concrete situation. Modelised consumer behaviour can be enriched by some variables like those of multi-attribute models.

The results of this investigation thus help demonstrating the feasability of building cellular automata-based behavioural modules that can express a whole range of individual consumption reactions and a variety of socio-economic environments. Other players, like the Stock Exchange and the State might be integrated in that analysis ( $c f$. the suggestions in Deissenberg, (1996)).

As a conclusion, the model shows the interest of resorting to cellular automata for the comprehension and simulation of consumer goods markets where individual relations come into play. This new tool is easy to implement and fit to describe and analyse complex economic and relational phenomena.

Acknowledgments. Special acknowledgement to Jean-Charles Khalifa, University of Poitiers, for his friendly and invaluable help.

\section{Appendices: tests in the CAMAC model}

Number of tests: 30 tests per variant with a maximum 9,999 periods per test.

Default hypothesis in tests:

- $24 \times 24$-cell torus containing 576 individuals

- 3 products

- Moore's neighbourhood

- No nonconformism, no brand loyalty, no variety search

- Purchases made each period.

$m$ : number of periods simulated before stable final state sets in.

The difference in $m$ averages between the resulting final state and the standard model's final state may be significant at the trust threshold 95\% (SIG) or non-significant (NS). $\sigma$ is the standard deviation. 


\section{Appendix 1: Relational behaviour}

\begin{tabular}{|c|c|c|}
\hline Behaviour & Market time path & Final state \\
\hline Imitation (standard model) & $\begin{array}{l}\text { Fluctuating structures, then duopoly } \\
\text { and monopoly }\end{array}$ & $\begin{array}{l}m=441.5 \\
\sigma=332.6\end{array}$ \\
\hline Initial market segmentation & Slow convergence towards monopoly & $\begin{array}{l}m=605.6 \sigma=259.2 \\
\text { SIG }\end{array}$ \\
\hline Generalised nonconformism & $\begin{array}{l}\text { Alternating structure with } 2 \text { or } 3 \text { surviving } \\
\text { products }\end{array}$ & No stable final state \\
\hline $\begin{array}{l}\text { Nonconformism for } 1 / 24 \\
\text { of individuals }\end{array}$ & $\begin{array}{l}\text { Chaotic structure without a dominating } \\
\text { product }\end{array}$ & No stable final state \\
\hline $\begin{array}{l}4 \text { opinion leaders for one } \\
\text { of the products }\end{array}$ & $\begin{array}{l}\text { Absolute domination of product prescribed } \\
\text { by leader }\end{array}$ & $m=488.9 \quad \sigma=486.9$ \\
\hline $\begin{array}{l}\text { Sensitivity to others } \\
\text { Von Neumann's neighbourhood }\end{array}$ & $\begin{array}{l}\text { 1/3 cases: oscillations } \\
\text { 2/3 cases: monopoly }\end{array}$ & $\begin{array}{l}m=969.2 \sigma=526.3 \\
\text { SIG }\end{array}$ \\
\hline $\begin{array}{l}\text { Sensitivity to others } \\
50 \% \text { density }\end{array}$ & $\begin{array}{l}\text { Frozen areas with monopoly in } 80 \% \\
\text { of situations }\end{array}$ & $\begin{array}{l}m=848.4 \sigma=386.2 \\
\text { SIG }\end{array}$ \\
\hline
\end{tabular}

\section{Appendix 2: Non-relational behaviour}

\begin{tabular}{|l|l|l|}
\hline Behaviour & \multicolumn{1}{|c|}{ Market time path } & \multicolumn{1}{c|}{ Final state } \\
\hline $\begin{array}{l}\text { Brand loyalty } \\
\varphi=0.9\end{array}$ & $\begin{array}{l}\text { Slow convergence towards } \\
\text { monopoly }\end{array}$ & $\begin{array}{l}m=621.8 \sigma=75.2 \\
\text { SIG }\end{array}$ \\
\hline Generalised variety search & Chaotic structure with strong cell alternation & No stable final state \\
\hline $\begin{array}{l}\text { Variety search for 1/24 } \\
\text { of individuals }\end{array}$ & Duopoly, then chaotic fluctuations & No stable final state \\
\hline $\begin{array}{l}\text { Mobility for 1/12 of individuals } \\
\text { 9-member families (autocratic) }\end{array}$ & $\begin{array}{l}\text { Slow convergence towards } \\
\text { monopoly } \\
\text { monopoly }\end{array}$ & $\begin{array}{l}\text { Sagnergence towards } \\
\text { SIG }\end{array}$ \\
\hline $\begin{array}{l}\text { 4-member families (autocratic) } \\
\text { Moderately fast convergence towards }\end{array}$ & $\begin{array}{l}m=66.4 \sigma=28.9 \\
\text { SIG }\end{array}$ \\
\hline $\begin{array}{l}\text { 4-member families (decentralised } \\
\text { democratic) }\end{array}$ & $\begin{array}{l}\text { Convergence towards monopoly } \\
\text { SIG }\end{array}$ \\
\hline
\end{tabular}




\section{Appendix 3: Socio-economic parameters}

\begin{tabular}{|l|l|l|}
\hline Parameters & \multicolumn{1}{|c|}{ Market time path } & \multicolumn{1}{|c|}{ Final state } \\
\hline $\begin{array}{l}\text { Market size } \\
(12 \times 12 \text { cells })\end{array}$ & $\begin{array}{l}\text { Fast convergence towards } \\
\text { monopoly }\end{array}$ & $\begin{array}{l}m=187.7 \quad \sigma=96.1 \\
\text { SIG }\end{array}$ \\
\hline $\begin{array}{l}\text { Market size } \\
(36 \times 36 \text { cells })\end{array}$ & $\begin{array}{l}\text { Slow convergence towards } \\
\text { monopoly }\end{array}$ & $\begin{array}{l}m=2,377.0 \quad \sigma=1,601.9 \\
\text { SIG }\end{array}$ \\
\hline $\begin{array}{l}\text { High inter-individual distance } \\
(8 \times 72 \text { cells })\end{array}$ & Very slow convergence towards monopoly & $\begin{array}{l}m=2,545.5 \quad \sigma=1,664.8 \\
\text { SIG }\end{array}$ \\
\hline 2 competing products & $\begin{array}{l}\text { Moderately fast convergence towards } \\
\text { monopoly }\end{array}$ & $\begin{array}{l}m=376.5 \quad \sigma=258.3 \\
\text { NS }\end{array}$ \\
\hline 4 competing products & $\begin{array}{l}\text { Moderately slow convergence towards } \\
\text { monopoly }\end{array}$ & $\begin{array}{l}m=737.1 \quad \sigma=524.3 \\
\text { SIG }\end{array}$ \\
\hline $\begin{array}{l}\text { Durable goods } \\
(10 \text { periods })\end{array}$ & Very slow convergence towards monopoly & $\begin{array}{l}m=2,260.8 \quad \sigma=1,632.9 \\
\text { SIG }\end{array}$ \\
\hline
\end{tabular}

\section{References}

Bass F.M. (1969) A New Product Growth Model for Consumer Durables, Management Science $15(5)$.

Bhargava S.C., Kumar A., Mukherjee A. (1993) A Stochastic Cellular Automata Model of Innovation Diffusion, Review Technological Forecasting and Social Change 44.

Casti J. (1991) Searching for Certainty, Ed. William Morrow.

Deissenberg Ch. (1996) A Simple Cellular Automaton Model of Complex Consumption Behavior, 3e Rencontre internationale ACSEG, Nantes.

Dubois B. (1994) Comprendre le consommateur, 2nd edition, Ed. Dalloz.

El Ouardighi F., Tapiero C.S. (1997) Modèles de diffusion en marketing, Revue Recherche et Applications en Marketing, 12 (4).

Engel J.F., Blackwell R.D., Miniard P.W. (1993) Consumer Behavior, 7th edition, The Dryden Press.

Fuks H., Boccara N. (1995) Cellular Automata Models for Diffusion of Innovations, Proceedings of the 6th Meeting on Instabilities and Nonequilibrium Structures, Santiago.

Fuks H., Boccara N. (1996) Modeling Diffusion of Innovation with Probabilistic Cellular Automaton, Spring School on Cellular Automata, Saissac.

Langlois A., Phipps M., (1997) Automates cellulaires, Ed. Hermès.

Margolus N., Toffoli T. (1987) Cellular Automata Machines: A New Environment for Modeling, The M.I.T. Press.

Nord W.R., Peter J.P. (1980) A Behavior Modification Perspective on Marketing, Journal of Marketing 44.

Phipps M. (1989) Dynamical Behavior of Cellular Automata under the Constraint of Neighborhood Coherence, Geographical Analysis, 21.

Robert-Demontrond Ph., Thiel D. (1996) Définition d'un programme de recherche connexionniste sur les trajectoires de marché, $3^{\mathrm{e}}$ Rencontre internationale ACSEG, Nantes. 
Solomon M.R. (1995) Consumer Behavior, 3rd edition, Ed. Allyn \& Bacon / Simon \& Schuster, Needham Heights.

Ter Haserborg F., Massen A. (1998) Le phénomène du comportement de recherche de variété, Revue Recherche et Applications en Marketing 13.

Wolfram S. (1986) Theory and Applications of Cellular Automata, World Scientific Publishing Company. 